\title{
Spontaneous Basilar Artery Dissection: A Case Report and Literature Review
}

\section{Dissecção espontânea da artéria basilar: análise de caso e revisão da literatura}

\author{
Marx Lima de Barros Araújo ${ }^{1}$ Benjamim Pessoa Vale ${ }^{2}$ \\ Paulo César de Jesus Gonçalves Júnior ${ }^{4}$
}

Lívio Pereira de Macêdo ${ }^{3}$ João Cícero Lima Vale ${ }^{3}$

Address for correspondence Marx Lima de Barros Araújo, MD, Instituto de Neurociências, Rua Bartolomeu de Vasconcelos, 2440, Ilhotas, Teresina, PI, Brazil 64.015-030

(e-mail: marx.neuro@gmail.com).

\section{Keywords}

- dissection

- basilar artery

- dissecting aneurysm

\section{Resumo}

\section{Palavras-chave}

- dissecação

- artéria basilar

- aneurisma dissecante
Spontaneous basilar artery dissection is a rare condition and a diagnostic challenge with a high potential for morbidity and mortality if untreated. It has an estimated incidence of 1 to 1.5 cases per 100,000 people. Few cases have been described in the literature up to the present day. The clinical outcomes, prognosis and treatment remain uncertain. The authors report the rare case of a 55-year-old female patient who presented to the Interventional Neuroradiology service at Hospital São Marcos, Teresina, in the state of Piauí, Brazil, with a history of severe headache located in the occipital region and in the nape with no improvement using common analgesics. A magnetic resonance imaging of the brain showed a saccular dilatation in the basilar artery, and a digital cerebral angiography showed a basilar artery dissection associated with a dissecting aneurysm.

A dissecção espontânea da artéria basilar é uma patologia rara, de difícil diagnóstico e com elevado potencial de morbidade e mortalidade. Estima-se uma incidência aproximada entre 1 e 1,5 caso para cada 100 mil pessoas. Poucos casos foram descritos na literatura até hoje. O curso clínico, prognóstico e tratamento ainda são incertos. Os autores relatam o caso de uma paciente do sexo feminino, de 55 anos, que se apresentou ao Serviço de Neurorradiologia Intervencionista do Hospital São Marcos, em Teresina capital do Piauí, Brasil, com queixa de cefaleia de forte intensidade localizada na região occipital e na nuca, refratária aos analgésicos comuns. Exames de neuroimagem mostraram dilatação sacular adjacente à artéria basilar, e uma angiografia digital por subtração evidenciou dissecção na artéria basilar associada à formação de aneurisma dissecante. received

September 18, 2015 accepted

November 23, 2015

published online

February 23, 2016
DOI https://doi.org/

10.1055/s-0036-1572506. ISSN 0103-5355.
Copyright $\odot 2018$ by Thieme Revinter

Publicações Ltda, Rio de Janeiro, Brazil
License terms

()ㅇㅇ $\Theta \circledast$ 


\section{Introduction}

Basilar artery dissection (BAD) is a clinical condition of rare incidence and difficult to diagnose, with high morbidity and mortality rates. ${ }^{1,2}$ In the last decades, with important advances in neuroimaging techniques, mainly non-invasive, such as angiotomography and angioresonance, an increase in the diagnosis of this pathology has been observed. The dissection of cervical arteries (carotid and extracranial vertebral arteries) or of cerebral arteries accounts for only $2 \%$ of all cases of ischemic stroke when analyzed at all ages. However, when we consider only young patients ( $<45$ years of age), this rate can reach higher values, reaching ranging from 10 to $25 \%$. The incidence of BAD is $\sim 1$ to 1.5 cases per 100,000 people. ${ }^{3,4}$ One study showed an even lower incidence, corresponding to 0.25 cases per 100,000 people. ${ }^{5}$ Even with the advances in diagnostic methods, the etiology of most dissections remains unknown. ${ }^{1,3}$ Several cases have been attributed to cervicocranial trauma, surgical manipulation, congenital defect in the middle layer of the artery, fibromuscular dysplasia, connective tissue diseases, syphilis, arteritis, or migraine. However, it is rarely possible to demonstrate a causal relationship. ${ }^{6}$ Little is known about the clinical course, the prognosis, and the best form of treatment. This pathology should be considered particularly in the differential diagnosis of young adult patients who presented with subarachnoid hemorrhage or cerebral ischemia in the territory of the posterior circulation. ${ }^{1-4}$ Although some authors adopt a conservative behavior, the high risk of severity in the occurrence of BAD may render surgery (either conventional or endovascular) necessary in selected cases. ${ }^{7-9}$ In the present study, we report a rare case of spontaneous dissection of the basilar artery associated with the formation of a dissecting aneurysm, addressing a review of the literature on the subject.

\section{Case Report}

A 55-year-old female patient attended the Interventional Neuroradiology Service at Hospital São Marcos, in Teresina, in the state of Piauí, Brazil, presenting with a severe headache, incapacitating and pulsatile, in the occipital area and, which started 3 days before hospital admission, possibly associated with nausea, photo and phonophobia and without improvement with common analgesics. There was no report of altered consciousness, seizure, or focal neurological deficit. The patient denied a history of prior cervical or cranioencephalic trauma, and she did not have a history of neurosurgical procedures. With regard to clinical comorbidities, she reported only systemic arterial hypertension, for which she regularly used antihypertensive medication. There was no history of smoking or alcoholism. The general and neurological physical examinations were normal, and only pain facies were observed. For the diagnostic investigation, a magnetic resonance imaging (MRI) with contrast of the brain was requested, and it showed a saccular dilation of regular contours adjacent to the basilar artery. A subtraction digital angiography was then performed, which revealed a focal saccular dilation located in the proximal third of the basilar artery, adjacent to the reduction in the arterial caliber, indicative of segmental stenosis ( $\mathbf{F i g .} \mathbf{1}$ ), and a negative intraluminal image compatible with flap (-Fig. 2). A small asymmetric focal dilation was observed in the origin of the right antero-inferior cerebellar artery and contrast retention was observed in the late arterial phase of the angiographic examination (-Fig. 3). These findings are compatible with dissection in the basilar artery associated with the formation of a dissecting aneurysm.

\section{Discussion}

The spontaneous dissection of the basilar artery is a rare disease, but due to the high potential for morbidity and mortality, it should be promptly recognized and should be included in the differential diagnosis of young patients presenting with stroke, particularly in the posterior (vertebrobasilar) circulation. The gold standard for the therapeutic modality remains uncertain. ${ }^{3}$

A review of the literature by Masson et al ${ }^{10}$ found 38 cases of BAD and, of these patients, 30 (78.9\%) died. Yoshimoto et $\mathrm{al}^{8}$ reported 10 cases of BAD ( 4 ruptured and 6 nonruptured dissections). Of the four patients with rupture, one had a fatal outcome and two were severely incapacitated, while four of six patients who did not present rupture were incapacitated due to progression of ischemic events. Kim

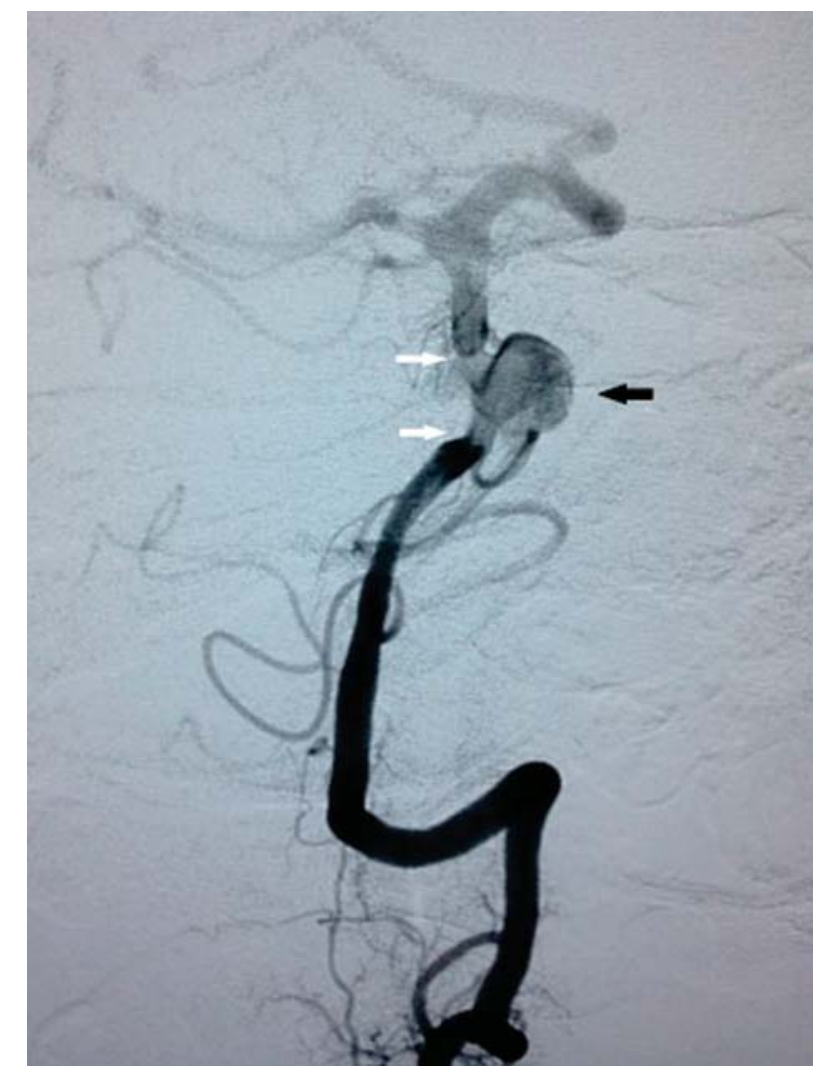

Fig. 1 Selective angiography of the left vertebral artery (oblique position) - saccular dilatation in the basilar artery compatible with dissecting aneurysm (dark arrow), adjacent to segmental stenosis (white arrows). 


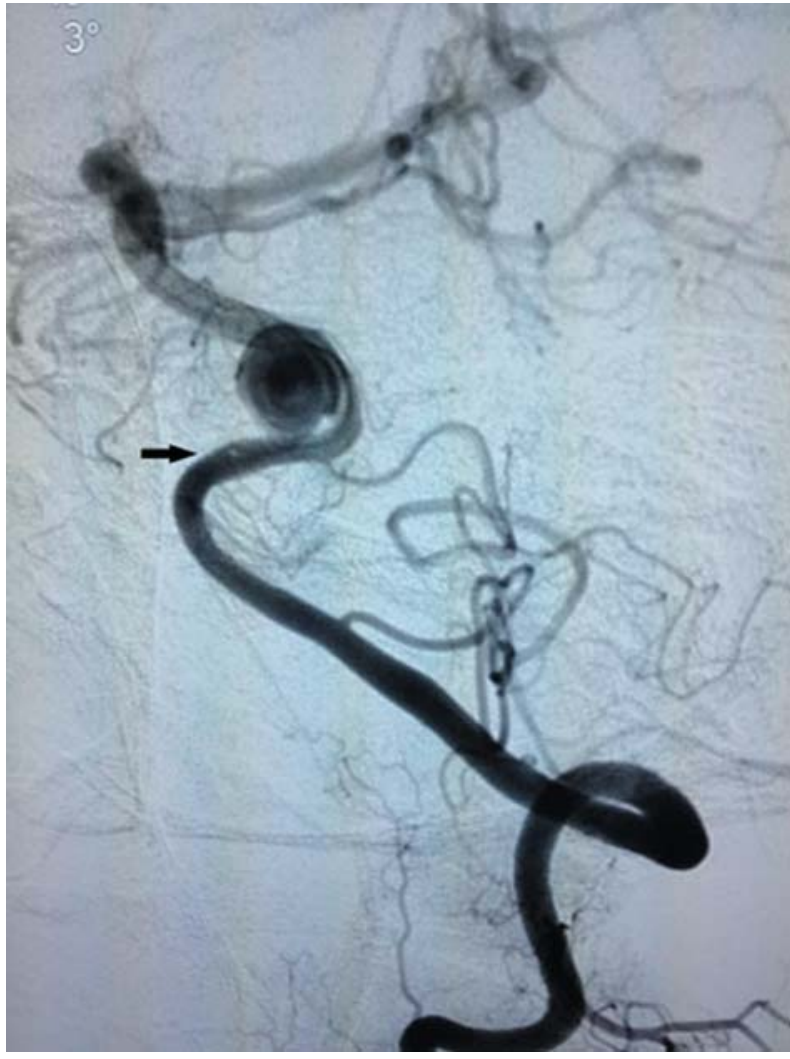

Fig. 2 Selective angiography of the left vertebral artery (side position) - image compatible with intraluminal flap (arrow).

et $\mathrm{al}^{3}$ performed a study with 21 cases of BAD. In 10 patients (47.6\%) there was rupture, and this was associated with a worse prognostic factor, with a mortality rate of $30 \%$ when compared with cases in which there was no rupture, with a zero-mortality rate. These same researchers showed that the group that was treated by the endovascular technique had a favorable outcome when compared with the conservatively managed group $(90.9 \%$ favorable outcome for the group treated endovascularly compared with $50 \%$ for the conservatively treated group).

Although several authors have reported spontaneous cure in cases of ruptured BAD and recommended conservative therapy, a review of the literature has shown that this condition imposes a high risk of death. A study by Nakahara et $\mathrm{al}^{11}$ reviewed 25 cases of ruptured BAD and showed mortality and morbidity rates of $20 \%$ and $40 \%$ respectively. For this reason, given the risks of bleeding and ischemic phenomena with severe outcome, conventional endovascular or surgical treatment may be necessary and should be observed in the analysis of each individual case.

\section{Conclusion}

The results of the reviewed studies suggest that ruptured BAD has a high risk of unfavorable outcome, whereas BAD without rupture has a relatively favorable outcome. Patients with this pathology treated with endovascular stent place-

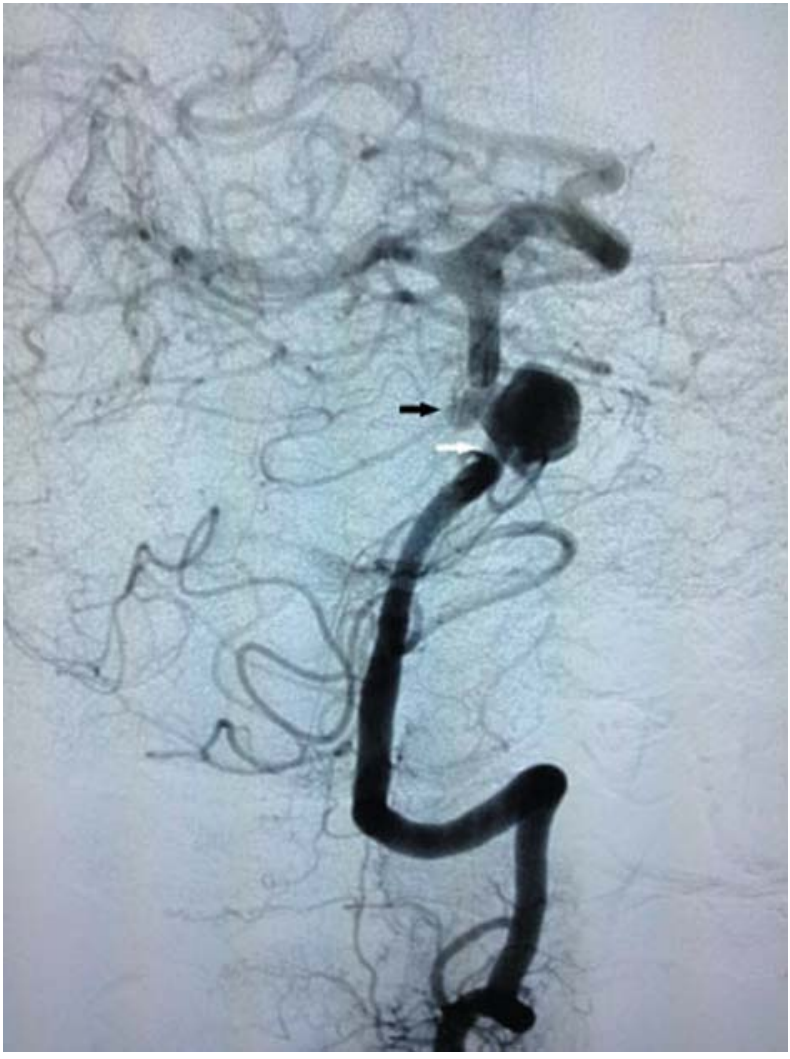

Fig. 3 Selective angiography of the left vertebral artery (oblique position) - small focal dilation in the origin of the right anteroinferior cerebellar artery (dark arrow), adjacent to segmental stenosis (white arrow).

ment and prominently controlled platinum springs, alone or in combination, tend to present a more favorable clinical outcome than those treated conservatively.

More studies are needed to better understand BAD and its natural evolution, in addition to the need for a definition of better therapeutic approach.

\section{Conflict of Interests}

The authors have none to declare

\section{References}

1 Yilmaz F, Arslan ED, Ozlem M, Kavalci C, Ciliz DS, Sever BS. A Rare Presentation of Stroke: Basilar Artery Disection. J Med Cases 2013;4(01):43-45

2 Tsao YW, Chen JH, Huang PH, Chen WL. Isolated basilar artery dissection-a rare cause of stroke in young adult. Am J Emerg Med 2013;31(09):1422.e3-1422.e5

3 Kim BM, Suh SH, Park SI, et al. Management and clinical outcome of acute basilar artery dissection. AJNR Am J Neuroradiol 2008;29 (10):1937-1941

4 Yoon WK, Kim YW, Kim SR, et al. Angiographic and clinical outcomes of stent-alone treatment for spontaneous vertebrobasilar dissecting aneurysm. Acta Neurochir (Wien) 2010;152(09): 1477-1486, discussion 1486

5 Ruecker M, Furtner M, Knoflach M, et al. Basilar artery dissection: series of 12 consecutive cases and review of the literature. Cerebrovasc Dis 2010;30(03):267-276

6 Chang V, Rewcastle NB, Harwood-Nash DCF, Norman MG. Bilateral dissecting aneurysms of the intracranial internal carotid arteries in an 8-year-old boy. Neurology 1975;25(06):573-579 
7 Pozzati E, Andreoli A, Padovani R, Nuzzo G. Dissecting aneurysms of the basilar artery. Neurosurgery 1995;36(02):254-258

8 Yoshimoto Y, Hoya K, Tanaka Y, Uchida T. Basilar artery dissection. J Neurosurg 2005;102(03):476-481

9 Hosoda K, Fujita S, Kawaguchi T, et al. Spontaneous dissecting aneurysms of the basilar artery presenting with a subarachnoid hemorrhage. Report of two cases. J Neurosurg 1991;75(04):628-633
10 Masson C, Krespy Y, Masson M, Colombani JM. Magnetic resonance imaging in basilar artery dissection. Stroke 1993;24(08): 1264-1266

11 Nakahara T, Satoh H, Mizoue T, Kawamoto H, Kohmo Y, Kurisu K. Dissecting aneurysm of basilar artery presenting with recurrent subarachnoid hemorrhage. Neurosurg Rev 1999;22 $(2-3): 155-158$ 